\title{
Al-In (Aluminum-Indium)
}

\section{H. Okamoto}

The Al-In phase diagram in [Massalski2] was redrawn from [1983Mur]. The miscibility gap in the liquid phase of this phase diagram is shown in Fig. 1 with a dashed line. This assessed line was created by depressing a thermodynamically calculated curve by up to about $25^{\circ} \mathrm{C}$ only around the critical point for consistency with available experimental data.

Since then, the miscibility gap was determined by viscosity measurements [1995Her] and surface tension/density measurements [2010Kab]. These results were in good agreement with the results of thermal analysis measurements [1965Pre]. The Al-In phase diagram shown in Fig. 1 with solid lines was calculated by [2010Kab] based on these new experimental results. The critical temperature of the miscibility gap was lowered by about $40{ }^{\circ} \mathrm{C}$ in comparison with [1983Mur].

\section{References}

1965Pre: B. Predel, Constitution and Thermodynamics of Miscibility Gap System, Z. Metallkd., 1965, 56(11), p 791-798, in German

1983Mur: J.L. Murray, The Al-In (Aluminum-Indium) System, Bull. Alloy Phase Diagr., 1983, 4(3), p 271-278

1995Her: F. Herwig and W. Hoyer, An Indication of Predecomposition Phenomenon of Liquid Al-In Alloys Above the Binodal Temperature Found by Viscosity Investigations, Mater. Sci. Eng. A, 1895, 190, p L5L8

2010Kab: I. Kaban, S. Curiotto, C. Chatain, and W. Hoyer, Surface, Interfaces and Phase Transitions in Al-In Monotectic Alloys, Acta Mater., 2010, 58, p 3406-3414

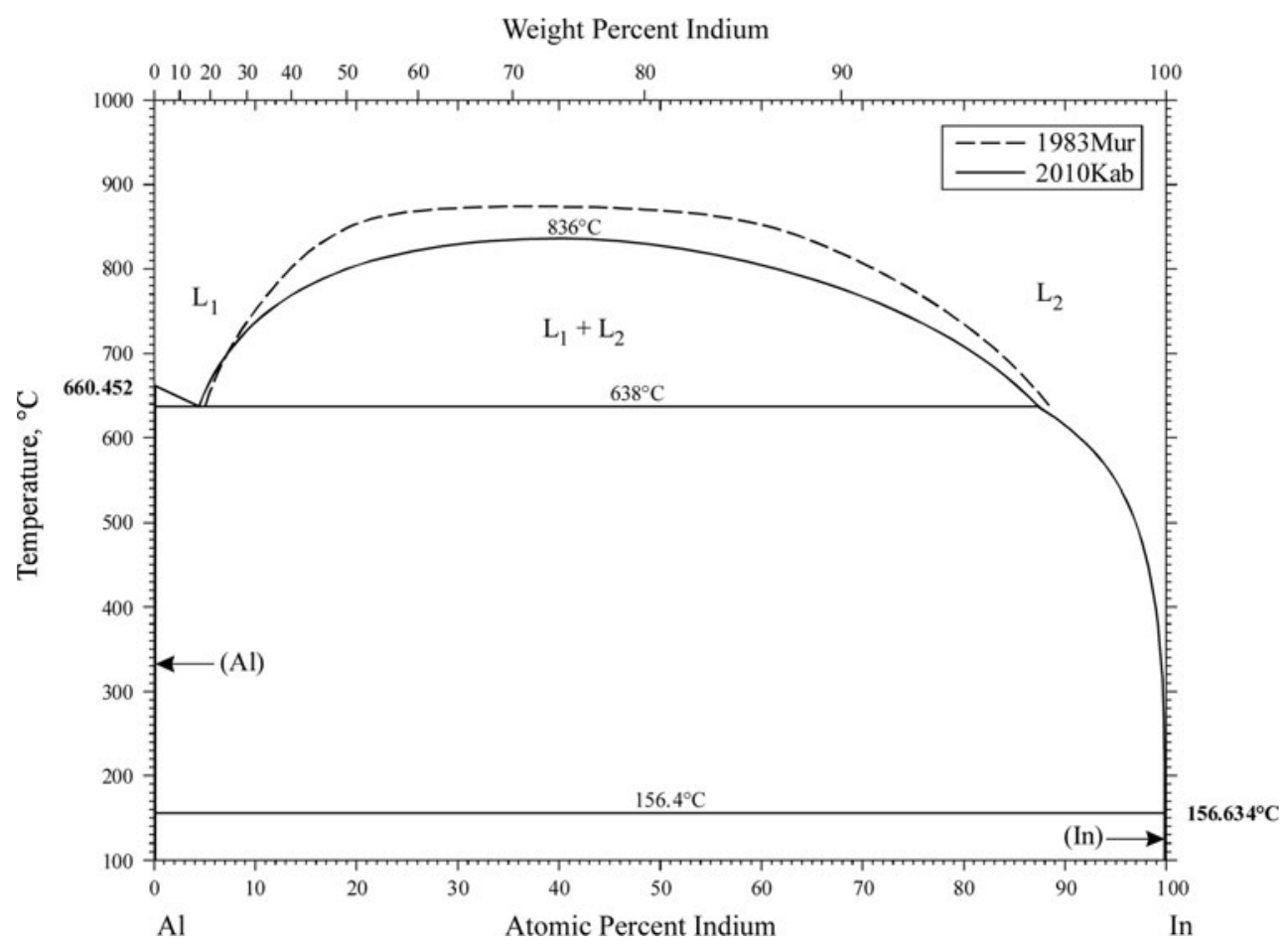

Fig. 1 Al-In phase diagram 